\title{
Comparison of Double Exponential Smoothing for Holt's Method and Artificial Neural Network in Forecasting the Malaysian Banking Stock Markets
}

\author{
Bahtiar Jamili Zaini ${ }^{*}$, Rosnalini Mansor ${ }^{1}$, Zahayu Md Yusof ${ }^{1,2}$, Darmesah Gabda³ and Wong Kah Seng ${ }^{1}$ \\ ${ }^{1}$ School of Quantitative Sciences, Universiti Utara Malaysia, 06010 UUM Sintok, Kedah, Malaysia \\ ${ }^{2}$ Institute of Strategic Industrial Decision Science Modeling (ISIDM), School of Quantitative Sciences, Universiti Utara \\ Malaysia, 06010 UUM Sintok, Kedah, Malaysia \\ ${ }^{3}$ Faculty of Science and Natural Resources, Universiti Malaysia Sabah, Jalan UMS, 88400 Kota Kinabalu Sabah
}

\begin{abstract}
Forecasting stock market has been the centre of attraction among investors for a long period of time. Investors are always forecasting their return on investment in the stock market before they start to invest. In this study, to forecast on the stock market price, the monthly closing stock prices data from the Malaysian stock markets, namely AMoo1 Berhad, CIoo2 Berhad, HLoo3 Berhad and PBoo4 Berhad from 2008 to 2017, are examined for predictability results using Double Exponential Smoothing (DES) for Holt's method and Artificial Neural Network (ANN). The data is partitioned into two parts due to different purposes.A sample data consisting of 96 months data from 2008 to 2015 was used for the estimation parameter and modeling part. Meanwhile, the evaluation part to validate the DES for Holt's method and ANN was conducted using out-of-sample data involving 24 months data from 2016 to 2017. Three error measurements, MAD, MSE and RMSE, have been used in the evaluation to compare the performance of these two forecasting methods. The statistical analysis results show that Holt's method is superior to ANN model and when using real values, it could accurately predict future price movements in the Malaysian stock markets. The outcomes from this study suggest that it is worthwhile to investigate the predictability and profitability of forecasting models.
\end{abstract}

Keywords: Artificial Neural Network, Double Exponential Smoothing, Stock Market, Time Series Forecasting Models

\section{INTRODUCTION}

Stock Market is where public company's stocks and bonds are issued and traded either through exchange, purchase or sale through public trades. In common terms, stock market is a market in which companies issue their share of publicly held and can be traded through exchange. Forecasting of stock price is a very challenging process, as it aims to determine the future value of a company stock. The risk and profit from stock market activities have always been a popular and central topic in financial and academic studies due to profitable activities. Therefore, it is important to predict the stock price.

However, the stock market is hard to predict. It has a lot of information and high uncertainty. Many factors like companies, politics, individual changes and even climate, influence the stock market. Stock markets have affected the variation of the market's economy across the globe, making investors to place emphasis on this (Sureshkumar, 2011).

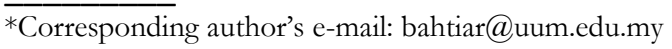


According to them, a country's growth might depend on the expression of stock market, if it rises, then the country's economy will become higher. In other words, if a country's stock market goes down, the economy of the country will be slow.

Therefore, a study on forecasting stock price has become a crucial need. There have been many methods for investigating the stock market price from classical to modern methods. Among popular classical methods are regression, exponential smoothing, Box-Jenkin and moving average method, to name a few. Artificial neural network (ANN), fuzzy method and support vector machine (SVM) method are considered as modern methods. A research done by Qiu, Song, \& Akagi, (2016) and Göçken, Özçalici, Boru, \& Dosdołru, (2016) used ANN to predict stock prices. Both studies show that a hybrid ANN forecasting model outperformed the traditional ANN forecasting model. Meanwhile, Zaidi \& Amirat (2016) used logistics regression and neural network to forecast stock market trends. The study revealed that neural network gave high prediction accuracy compared to logistic regression. The fuzzy time series (FTS) method is also a part of the stock market forecasting method. This method is quite different with other stock market forecasting methods as the FTS method is able to analyse time series containing linguistic variable in the data. For instance, Javedani Sadaei \& Lee, (2014) and Mirzaei Talarposhti et. al., (2016) applied FTS in stock market forecasting. The FTS can also be applied in other fields, such as students enrolment(Mansor et. al., 2017; Mansor et. al., 2018) and electricity load demand forecasting (Mansor et. al., 2016a, 2016b).

Although the Exponential-smoothing technique is one of the classical forecasting methods, the method is still relevant because it is easy and can be applied quickly, while taking into account any trend in the data. Moreover, the smoothing parameter in the model also contributes to the significant model for forecasting purpose. Kuzhda, (2014) applied two basic models in the exponential smoothing method, and simple and double exponential smoothing method for stock price forecasting. The study found that the exponential smoothing method is effective in providing valuable decision and information for managers and investors (Kuzhda, 2014).
This research aims to find out a good forecasting model to obtain higher accuracy in predicting stock price. In order to achieve the main aim, two research objectives are highlighted:

i. To model the Malaysian stock markets using a statistical forecasting model of Double Exponential Smoothing for Holt's method and an Artificial Intelligence model of Artificial Neural Network using modelling part of data.

ii. To evaluate the models' performance by comparing forecasting measurement error in the evaluation part of data.

\section{METHODOLOGY}

\section{A. Data Preparation}

In this research work, four major stocks in Malaysian banking will be observed. A set of secondary data was gained/gathered from the Bursa Malaysia website. The business area of the selected stocks is from the banking sector, which are AMoo1 Berhad, CIoo2 Berhad, HLoo3 Berhad, and PBoo4 Berhad. We chose these stocks not only because they are amongst the largest stocks in the Malaysian region, but also because they are growing aggressively in recent years.

The monthly closing prices of AMoo1 stock, CIoo2 stock, HLoO3 stock, and PBoo4 stock collected from January 4, 2008 to December 31, 2015 for modelling part consist of 96 months of data. An out-of-sample data used as testing period is collected 2 years from January 4, 2016 to December 29, 2017.

\section{B. Method of Data Analysis}

\section{Double Exponential Smoothing (Holt's Method)}

Holt (1957) extended simple exponential smoothing method to allow the forecasting of data with a trend. Holt's 2 parameters in double exponential smoothing method are best applied to time series that have a prevalent linear trend, but does not exhibit seasonal trend.

Conceptually, this Holt's method is similar to Brown's double exponential smoothing method. Firstly, we need to obtain the forecasts value. Then, repeat the simple 
exponential smoothing method on the forecast values. The techniques smooth the trend and slope in time series by using different smoothing constants for each.

\section{Step 1:}

Determine the initial value $\alpha$ and $\beta$ from range 0 to $1, S_{1}$ is the first data value, and $\mathrm{T}_{1}$ is equal to zero.

\section{Step 2:}

The application of Holt's smoothing approach requires three equations. Equations 1-3 are formulas of Holt's method with the level equation, trend equation, and forecast equation respectively.

First, compute the exponentially smoothed series:

$S_{t}=\alpha y_{t}+(1-\alpha)\left(S_{t-1}+T_{t-1}\right)$

Then, to estimate the trend:

$T_{t}=\left(S_{t}-S_{t-1}\right)+(1-\beta) T_{t-1}$

Finally, to forecast a value mperiods into the future:

$\hat{y}_{t+m}=S_{t}+T_{t}(m)$

where

$S_{t}=$ the estimate of the level of series at time t;

$T_{t}=$ the estimate of the trend (slope) of series at time $\mathrm{t}$;

$\alpha=$ the smoothing parameter for the level, $0 \leq \alpha \leq 1$;

$\beta=$ the smoothing parameter for the trend, $0 \leq \beta \leq 1$;

\section{Step 3:}

Compute the errorto find error measures criteria.

Step 4:

Using Solver function in Excel to find the best $\alpha$ and $\beta$ that minimize error measures criteria.

\section{Artificial Neural Network (ANN)}

Artificial Neural Network (ANN) is a machine-learning algorithm that tries to simulate the concept of human brain (G. Zhang et. al., 1998). The ANN model is characterized by a network of three layers, which are input, hidden and output layer. The layers are connected by acyclic links. There may be more than one hidden layer. The nodes in various layers are also known as processing elements. ANN tries to identify any patterns in the input data, and then learn from historical data. Based on its known previous knowledge, ANN could provide general results.

\section{Forecasting Models’ Performance Measures}

Normally, the performance of forecasting technique is measured by the forecasting error. Among all of the different error measures found, those used in this work are Mean Absolute Deviation (MAD), Mean Squared Error (MSE), and Root Mean Squared Error (RMSE).

\section{DATA ANALYSIS AND RESULT}

This study examines forecasting of time series stocks in Malaysia stock markets from 2008 to 2017 using Holt's method and ANN. Preliminary analysis for the four stocks markets: AMoO1, CIoO2, HLoo3, and PBoO4 are exhibited in Figure 1.

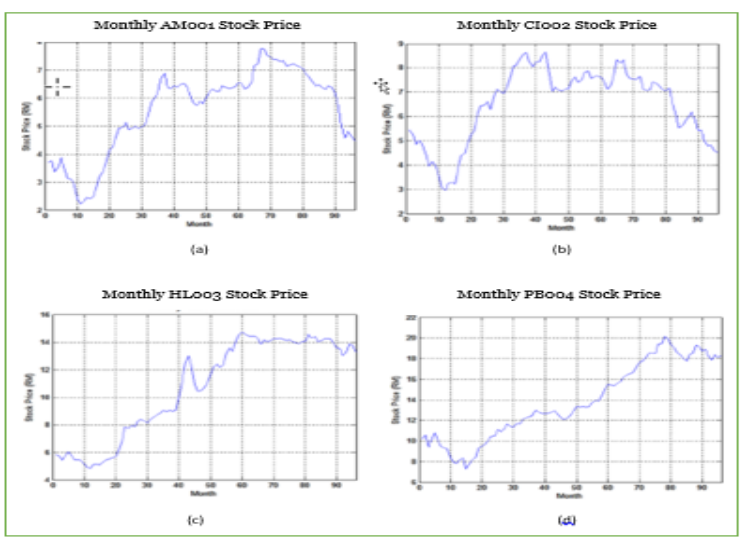

Figure 1. Charts of AMoo1, CIOO2, HLoo3, and PBoo4 Monthly Stock Price for In-Sample Period, 2008 to 2015

Figure 1 presents the time series plots of four different stocks. Overall, the results demonstrate that all four stock markets have the same pattern of time series. We can observe that the stock prices of four different stocks are fluctuated. The beginning of the trend decreases, and upward trend can 
be observed for the following at certain peak, and then, lastly falls again at the end of year 2015 .

The performances of the Holt's method and ANN model for AMoo1 stock, CIoO2 stock, HLOO3 stock, and PBoO4 stock are presented in Table 1. The corresponding error measures for Holt's method and ANN model indicate the accuracy of the stock prices in these two models.

Table 1. A Comparison of Error Measures for Different Models

\begin{tabular}{|l|l|c|c|}
\hline Stock & Method & Holt's & ANN \\
\hline \multirow{4}{*}{ AMo01 } & MAD & 0.1564 & 0.7705 \\
\cline { 2 - 4 } & MSE & 0.0419 & 0.8181 \\
\cline { 2 - 4 } & RMSE & 0.2046 & 0.9045 \\
\hline \multirow{4}{*}{ CI002 } & MAD & 0.2572 & 1.6124 \\
\cline { 2 - 4 } & MSE & 0.0905 & 3.6279 \\
\cline { 2 - 4 } & RMSE & 0.3008 & 1.9047 \\
\hline \multirow{3}{*}{ HL003 } & MAD & 0.3036 & 0.7384 \\
\cline { 2 - 4 } & MSE & 0.1873 & 0.9932 \\
\cline { 2 - 4 } & RMSE & 0.4328 & 0.9966 \\
\hline \multirow{3}{*}{ PBo04 } & MAD & 0.1362 & 0.9863 \\
\cline { 2 - 4 } & MSE & 0.0255 & 1.3338 \\
\cline { 2 - 4 } & RMSE & 0.1596 & 1.1549 \\
\hline
\end{tabular}

It can be seen that in the out-of-sample test period, Holt's method clearly outperforms the ANN model; owing to the forecast errors of the four stock markets for out-of-sample period, which are lower, indicating the Holt's method is the most appropriate forecasting model. The forecast diagrams of four different stocks for the whole data period are graphically depicted in Figure2. As a result, the forecast values are very close to actual prices, so Holt's method is the most appropriate stock price prediction model as it outperforms in prediction accuracy. Therefore, we can employ this model to other time series stock markets to predict future price movements. In this study, Holt's method was used to forecast the Malaysian stock markets and produced comparative results with least error measures in different periods and markets.

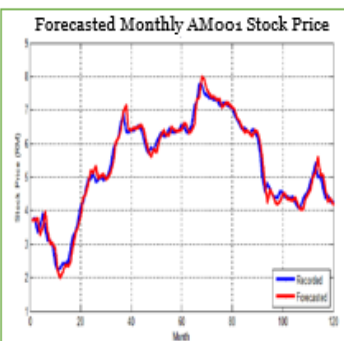

(a)

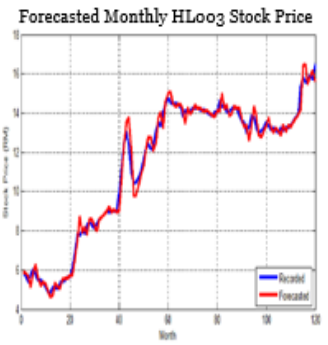

(c)

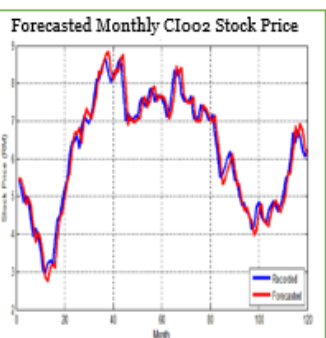

(b)

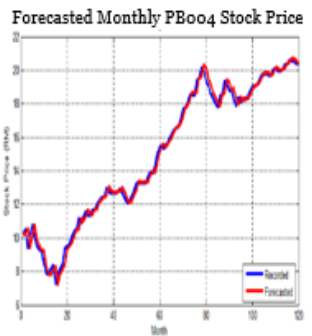

(d)
Figure 2. Charts of AMoO1, CIoo2, HLoO3, and PBoO4 Forecasted Monthly Stock Price for Data Period, 2008 to 2017

\section{CONCLUSION}

This paper presented the forecast of monthly closing prices among four major stocks using the concept of Holt's method and ANN model. The results show that the statistical forecasting method, Holt's model, is superior to ANN model and when using real values, it could accurately predict future price movements of the Malaysian stock markets. Thus, Holt's method can help reducing feasible risks and making profit.

This research is limited in the sense that the two forecasting models considered here cannot guarantee a successful stock price prediction model akin to the forecasting techniques since other methods, including statistic methods, technical analysis, and artificial intelligence models are needed prior to help investors to obtain adequate information and produce forecasts. Further analysis to assess the merits and demerits of the proposed models, as well as the possible alternatives to a stock forecasting area, needs to be undertaken.

\section{ACKNOWLEDGEMENTS}

The authors are grateful for the financial support received from Universiti Utara Malaysia under the Research 
Generating University Grant (S/O Code: 13877). We also

thank the anonymous reviewers for their useful suggestions.

\section{REFERENCES}

Göçken, M., Özçalici, M., Boru, A., \& Dosdoru, A. T. 2016, Integrating metaheuristics andArtificial Neural Networks for improved stock price prediction. Expert Systems withApplications. 44, 320-331

Javedani Sadaei, H., \& Lee, M. H. 2014, Multilayer stock forecasting model using fuzzytime series. The Scientific World Journal, 2014(May). 10 pages.

Kuzhda, T. 2014, Exponential Smoothing For Financial Time Series Data Forecasting. Sotsial'no-Ekonomichni Problemy $i$ Derzhava - Socio- Economic Problems and the State, $10(1), 177-184$.

Levine, R., \& Zervos, S. 1998, Stock Markets, Banks, and Economic Growth. The American Economic Review, 88(3), 537-558.

Mansor, R., Kasim, M. M., \& Othman, M. 2016a, A Weighted Subsethood Mamdani Fuzzy Rules Based System Rule Extraction (MFRBS-WSBA) for Forecasting Electricity Load Demand - A Framework. Journal of Telecommunication, Electronic and Computer Engineering, 8(8), 97-102.

Mansor, R., Kasim, M. M., \& Othman, M. 2016b, The framework of weighted subset-hood Mamdani fuzzy rule based system rule extraction (MFRBS-WSBA) for forecasting electricity load demand. In International Conference on Applied Science and Technology 2016 (ICAST'16) (Vol. 1761, p. 020061). Langkawi: AIP
Publishing.

Mansor, R., Othman, M., \& Kasim, M. M. 2017, Fuzzy Reasoning Based Time SeriesForecasting Using Weighted. Advanced Science Letters, 23(9), 9094-9097.

Mansor, R., Zaini, B. J., Othman, M., \& Kasim, M. M. 2018, The Effect of Interval Length inWeighted Subsethood Fuzzy Time Series. In AIP Conference Proceeding (Vol. 1974, pp. 040017 1-040017-7). American Institute of Physics.

Mirzaei Talarposhti, F., Javedani Sadaei, H., Enayatifar, R., Gadelha Guimarães, F., Mahmud, M., \& Eslami, T. 2016, Stock market forecasting by using a hybrid model of exponential fuzzy time series. International Journal of Approximate Reasoning. 70(C). 79-78

Qiu, M., Song, Y., \& Akagi, F. 2016, Application of artificial neural network for the prediction of stock market returns: The case of the Japanese stock market. Chaos, Solitons and Fractals. 85. 1-7

Sureshkumar, K. K. \& Elango N. M. 2011, An Efficient Approach to Forecast Indian Stock Market Price and their Performance Analysis. International Journal of Computer Applications. 34(4). 44-49

Zaidi, M., \& Amirat, A. 2016, Forecasting Stock Market Trends By Logistic Regression and Neural Networks Evidence From Ksa Stock Market. International Journal of Economics, Commerce and Management United Kingdom, IV(6), 220-234. 